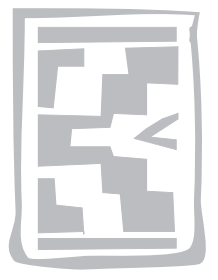

\title{
A survey of tick control methods used by resource-poor farmers in the Qwa-Qwa area of the eastern Free State Province, South Africa
}

\author{
M. HLATSHWAYO* and P.A. MBATI \\ Parasitology Research Programme, Qwa-Qwa Campus, University of the Free State \\ Private Bag X13, Phuthaditjhaba, 9866 South Africa
}

\begin{abstract}
HLATSHWAYO, M. \& MBATI, P.A. 2005. A survey of tick control methods used by resource-poor farmers in the Qwa-Qwa area of the eastern Free State Province, South Africa. Onderstepoort Journal of Veterinary Research, 72:245-249

A survey conducted in five villages in a resource-poor farming community in Qwa-Qwa, using the rapid rural appraisal technique and a questionnaire survey, showed that a significant proportion of the farmers ( $84 \%)$ use traditional or alternative methods to control ectoparasites, while $16 \%$ use commercial acaricides $\left(\chi^{2}=7.1 ; P \leq 0.05\right)$. Alternative control methods included the use of used engine oil, household disinfectant and paraffin. Killing of ticks was the main reason for control (40\%), with disease control being second $(20 \%)$. Other reasons given for controlling ticks were to prevent damage to teats, to provide animals with a clean appearance and to protect hides. Some $40 \%$ of farmers were aware of the effects of ticks on their animals. There is a need for farmer education that will provide information on integrated tick management and its advantages over absolute reliance on commercial acaricides.
\end{abstract}

Keywords: Acaricides, ectoparasites, tick control

\section{INTRODUCTION}

Ticks and the diseases they transmit are a major constraint to livestock improvement in many parts of the world. Animal farming in the communal areas of the eastern Free State Province is concerned mainly with the production of cattle, goats and sheep. The major tick species found on livestock in the Qwa-Qwa area of the eastern Free State are Rhipicephalus (Boophilus) decoloratus and Rhipicephalus evertsi evertsi (Hlatshwayo, Mbati \& Dipeolu 2002).

The use of acaricides in the control of ticks has improved the viability of cattle farming in the tick-

* Author to whom correspondence is to be directed. E-mail: hlatshwayom@qwa.uovs.ac.za

Accepted for publication 14 June 2005-Editor infested areas. Dipping in a plunge dip is one way in which ticks are controlled. During the early $20^{\text {th }}$ Century, the Veterinary Service of the then Department of Agriculture of South Africa initiated a tick control programme after the introduction of East Coast fever from East Africa (Norval 1994). Several measures were instituted by the Department, including dipping, which proved to be the most practical and effective. As a result it was widely adopted by farmers and later made compulsory by the State (Norval 1994). After the eradication of East Coast fever from South Africa, considered to have been achieved by 1960, compulsory dipping was abolished on white-owned farms. In the homelands, however, compulsory dipping continued to be enforced, because animal health authorities viewed the cattle in communal areas as a source of infection, with tick-borne diseases being of major con- 
cern. By continuing the dipping service, the Department hoped to reduce and, if possible, eradicate the tick population in these areas. Animals were marked after each dipping session, and unmarked animals were impounded (Masika, Sonandi \& Van Averbeke 1997). During the 1970s, management of the dipping service was handed over to the former homeland administrations. In most homelands, including Qwa-Qwa, livestock owners paid a fee for each animal dipped, and in others, fees were collected in the form of a grazing levy, payable annually (Steyn 1988). The dipping service was maintained by the new administrations, but enforcement of the dipping programme was gradually relaxed. When the homelands were re-incorporated into South Africa in 1994, the Provincial Departments of Agriculture accepted responsibility for the dipping service, supplying both personnel and chemicals. Subsequent years saw budgetary constraints causing the Department to suspend the supply of chemicals, which limited its contribution to the programme. The responsibility of purchasing dipping chemicals was left to the farming communities.

The objectives of the study were to assess present levels of participation by resource-poor livestock owners in tick control practices using acaricides. In addition, the reasons for their participation, and other tick control practices that are used by the target group in addition to acaricides were documented.

\section{MATERIALS AND METHODS}

The study was conducted in the Qwa-Qwa area of the eastern Free State Province. Study sites included Bochabela, Makeneng, Namahadi, Tseki and Lejwaneng. The target group consisted of resourcepoor livestock owners who rear cattle on communally managed rangeland.

The investigation was conducted in two phases. From February to April 1998, matrix ranking, diagramming and group interviews, which form part of the rapid rural appraisal (RRA) family of techniques (Chambers 1992) were used to obtain information from a total of 50 participants. The second phase of the study was conducted between February and April 1999 and consisted of a formal questionnaire survey. This survey enabled quantitative data, that was free of bias introduced by group dynamics, and that might affect similar data obtained using RRA techniques to be obtained (Chambers 1992). The design and content of the questionnaire were guided by the analysis of responses obtained in RRA meetings. The questionnaire was pre-tested for con- tent validity and reliability in a pilot survey of 50 respondents (ten in each of the above mentioned study sites).

Responses to the questionnaire were captured in Corel Quattro Pro (Corel Corporation and Corel Corporation Limited 1997). Most data were converted to percentages to simplify analyses. A Chi-square $\left(\chi^{2}\right)$ test was used to test for differences between the use of commercial acaricides and alternative methods of control. A significance level of $P \leq 0.05$ was used throughout the analyses (Barnard, Gilbert \& McGregor 1993).

\section{RESULTS}

\section{Level of participation in tick control using commercial acaricides}

Fig. 1 shows the tick control measures used by resource-poor farmers in communal areas of QwaQwa. Eight percent of farmers used pour-on acaricides, $4 \%$ used tick-grease and another $4 \%$ rarely participated in the dipping programmes.

\section{Tick control methods other than the use of commercial acaricides}

Fig. 2 shows the alternative tick control methods used by resource-poor farmers in Qwa-Qwa in comparison with commercial acaricides. Tick control measures were implemented by $70 \%$ of respon-



FIG. 1 Results of a questionnaire survey on tick control measures used by resource-poor farmers in communal land areas of Qwa-Qwa between February and April 1999 
dents of which $28 \%$ used commercial acaricides and $42 \%$ used alternative methods.

\section{Reasons for controlling livestock ticks}

Different reasons given by the Qwa-Qwa farmers for controlling ticks are given in Fig. 3 . The results show that many farmers were aware of the problems that ticks caused, hence the different reasons for their control.

\section{DISCUSSION}

\section{Level of participation in tick control using commercial acaricides}

Results of the questionnaire survey indicated that few participants used commercial acaricides (16\%). Eight percent of farmers consistently used pour-on acaricides, $4 \%$ used tick grease and another $4 \%$ rarely participated in the dipping programmes (Fig. 1). However, many farmers $(70 \%)$ perceived the use of commercial acaricides as beneficial, citing economical constraints as the main reason for their reduced level of participation.

\section{Tick control methods other than the use of commercial acaricides}

During the rapid rural appraisal meetings, $80 \%$ of farmers indicated that they experience high tick infestations and tick-related problems on their live-

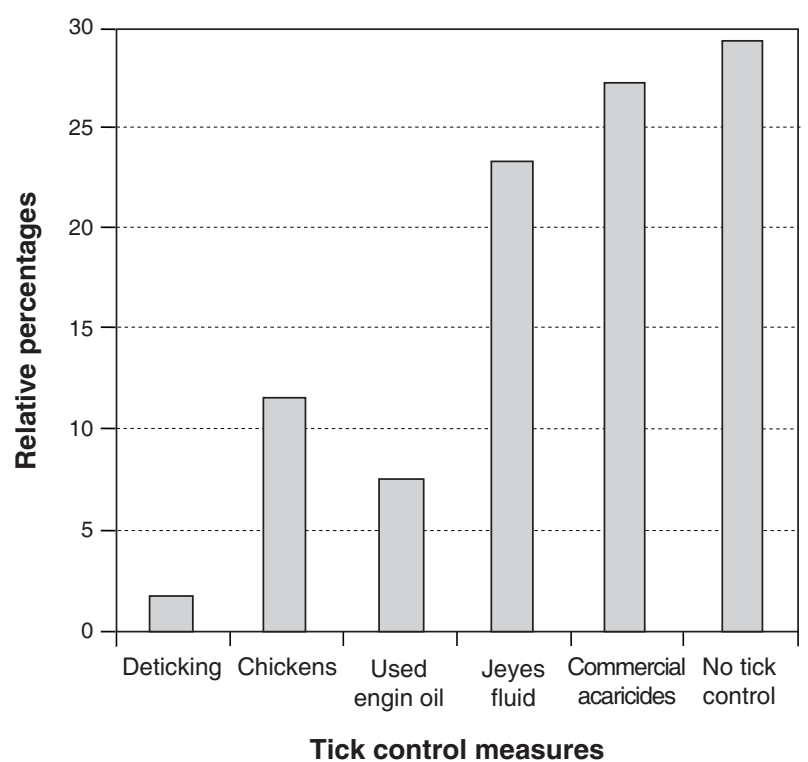

FIG. 2 Different tick control measures cited by resource-poor farmers of Qwa-Qwa during the RRA meetings between February and April 1998 stock but only $70 \%$ of these implemented any tick control measures. Out of the group of farmers that attempted to control ticks, $28 \%$ used commercial acaricides (Fig. 2).

During the RRA meetings $4 \%$ of the respondents indicated that chickens helped in controlling ticks. Some $24 \%$ of farmers used Jeyes fluid, a commercial household disinfectant and cleaner with a carbolic acid coefficient of 4-6 (Adcock Ingram). Twelve percent indicated that they prefer used engine oil as acaricide (Fig. 2).

The existing management system of returning cattle to pens near the homestead at dusk presents an ideal situation to use free-ranging chickens for tick control. Studies conducted on the consumption of ticks by chickens indicated that the use of chickens as part of an integrated tick management plan is feasible (Dreyer, Fourie \& Kok 1997).

Alternative tick control practiced according to respondents in the questionnaire survey are shown in Fig. 1. All respondents who participated in the survey indicated that they do control ticks, $84 \%$ using alternative tick control methods. Significantly more farmers used alternative tick control methods than commercial acaricides (Chi-square test: $\chi^{2}=7.1$, $P \leq 0.05)$. During the questionnaire survey more farmers indicated that they use alternative tick control methods $(84 \%)$ than they did during the RRA meetings $(42 \%)$.

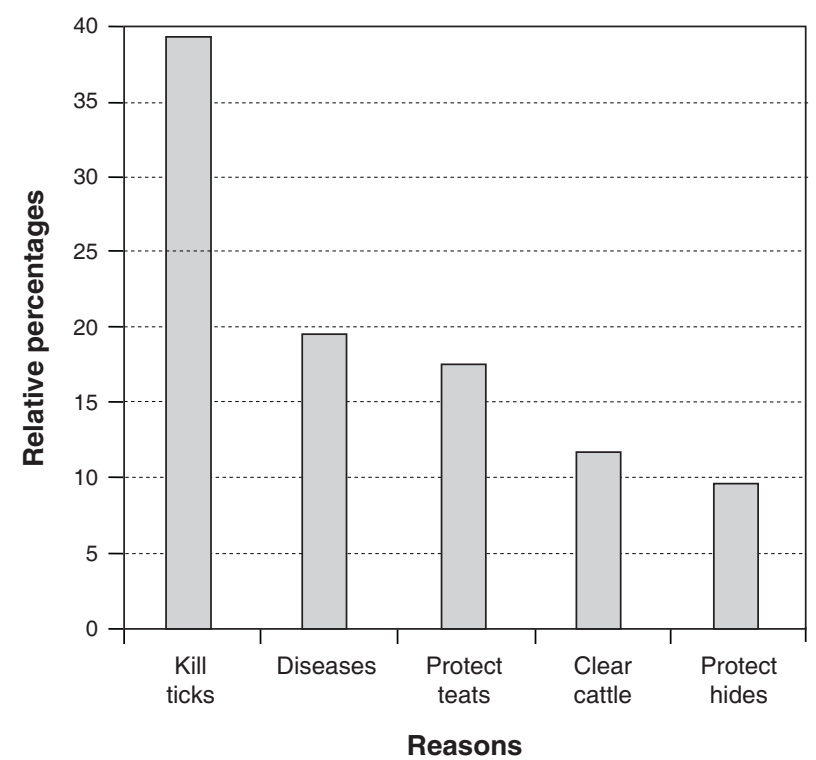

FIG. 3 Reasons given by the Qwa-Qwa farmers for controlling ticks during a questionnaire survey between February and April 1999 
Engine oil and Jeyes fluid were most commonly used as alternative tick control substances. Both substances are cheap and readily available, which may explain why farmers prefer them. Used engine oil, applied to livestock with a cloth, is utilised by $40 \%$ of the farmers. A quantity of $300-500 \mathrm{~m} \ell$ is rubbed into the pelage of each bovine with an evident high tick infestation. The oil is either bought or received free of charge from the various informal motor-repair garages along the roads in Qwa-Qwa. The efficacy of the oil as an acaricide has previously been estimated to be about $38.1 \%$ (Dreyer, Fourie \& Kok 1998).

About $34 \%$ of farmers in this study used Jeyes fluid as acaricide. This is either used separately or in a mixture with used engine oil. The Jeyes fluid is diluted with water and applied in the same manner as the engine oil. Only $10 \%$ of farmers used paraffin in a similar manner as the oil and Jeyes fluid.

\section{Reasons for controlling livestock ticks}

Reasons given by the farmers for tick control are shown in Fig. 3. Eradication of ticks to prevent them from sucking blood from livestock was the main motive (40\%). A tick survey during 1998-1999 in the eastern Free State (Hlatshwayo 2000) revealed that with heavy $R$. (B.) decoloratus infestations scales and crust formed on the skin. The direct effect of infestations with this tick is proportional to the numbers of successfully engorging ticks on the animal (Uilenberg 1992). A loss of $0.6-1.5 \mathrm{~g}$ of body mass per engorged $R$. (B.) microplus female has been documented in cross breed cattle in Australia (Sutherst, Maywald, Kerr \& Stegeman 1983). Results obtained in a study in a Bushveld region south-east of Groblersdal, indicated that a loss in weaning mass of calves whose dams were predominantly infested with $R$. (B.) decoloratus was even higher, and stood at between 8.0-9.0 $\mathrm{g}$ for each female tick engorging (Scholtz, Spickett, Lombard \& Enslin 1991). These studies demonstrate some negative effects of ticks on livestock and it appears that many farmers are conscious of these problems (40\%).

Only $20 \%$ of farmers were concerned about prevention of tick-borne diseases and not all the diseases that farmers perceived to be prevented by the application of acaricides are actually transmitted by ticks. Examples of the latter are anthrax and three-day stiff sickness (bovine ephemeral fever). This suggests that farmers perceive application of acaricides to be a disease control measure with an activity much broader than is actually the case. Avoiding damage to teats ranked third (18\%) amongst the reasons for tick control indicating the importance of milk as a major benefit derived from keeping cattle (Duvel \& Afful 1994; Masika et al. 1997).

\section{The future of tick control in the communal areas}

Indigenous Sanga and Zebu cattle which are predominantly reared by communal farmers have a high degree of tick and tick-borne disease resistance (Norval 1994) and require minimal tick control. This could range from a total absence of control in dry areas, to strategic control during the wet season in humid areas. In the eastern Free State, especially in Qwa-Qwa, the majority of resource-poor farmers rely on the traditional or alternative methods for controlling ticks and the reduced utilization of commercial acaricides is due to their high costs (Hlatshwayo 2000). This allows a certain number of ticks to continue feeding on the animals, hence possibly maintaining the enzootic stability of tick-borne diseases, such as anaplasmosis and babesiosis, in the area (Mtshali, De Waal \& Mbati 2004). Bos taurus lack the genetic tick resistance of the indigenous breeds and require intensive tick control for the greater part of the year in all but the dry climatic areas. In these cattle breeds intensive tick control may be reduced only when tick-borne diseases are controlled through an effective immunization programmes (Norval 1994).

No single method is adequate to control the complex problem of ticks and tick-borne diseases in South Africa and an integrated approach that involves especially the farmers should therefore be considered for the future.

\section{ACKNOWLEDGEMENTS}

We are grateful to the farmers who participated in this survey. This study was funded by the National Research Foundation and the University of the Free State.

\section{REFERENCES}

BARNARD, C.J., GILBERT, F.S. \& MCGREGOR, P.K. 1993. Asking questions in biology. Essex: Longman Scientific \& Technical.

CHAMBERS, R. 1992. Rural appraisal: rapid, relaxed and participatory. Brighton: Institute of Development Studies, University of Sussex (Discussion paper 311).

DREYER, K., FOURIE, L.J. \& KOK, D.J. 1997. Predation of livestock ticks by chickens as a tick-control method in a 
resource-poor urban environment. Onderstepoort Journal of Veterinary Research, 64:273-276.

DREYER, K., FOURIE, L.J. \& KOK, D.J. 1998. The efficacy of used-engine oil against ticks on cattle. Onderstepoort Journal of Veterinary Research, 65:275-279.

DUVEL, G.H. \& AFFUL, D.B. 1994. Human constraints in stock reduction and communal land management in a subsistence farming situation in South Africa. Research Report. South African Institute for Agricultural Extension, University of Pretoria.

HLATSHWAYO, M. 2000. Studies on ticks (Acari: Ixodidae) infesting cattle in the eastern Free State Province of South Africa: Epidemiology, biology and control. M.Sc. thesis, University of the North.

HLATSHWAYO, M., MBATI, P.A. \& DIPEOLU, O.O. 2002. Seasonal abundance of adult ixodid ticks infesting cattle belonging to resource-limited farmers in the north-eastern Free State Province of South Africa. Onderstepoort Journal of Veterinary Research, 69:1-6.

MASIKA, P.J., SONANDI, A. \& VAN AVERBEKE, W. 1997. Tick control by small-scale cattle farmers in the central eastern Cape Province. Journal of the South African Veterinary Association, 68(2):45-48.
MTSHALI, M.S., DE WAAL, D.T. \& MBATI, P.A. 2004. A seroepidemiological survey of blood parasites in cattle in the northeastern Free State, South Africa. Onderstepoort Journal of Veterinary Research, 70:67-75.

NORVAL, R.A.I. 1994. Vectors: Ticks, in Infectious diseases of livestock with special reference to Southern Africa, I, edited by J.A.W. Coetzer, G.R. Thompson \& R.C. Tustin. Cape Town: Oxford University Press.

SCHOLTZ, M.M., SPICKETT, A.M., LOMBARD, P.E. \& ENSLIN, C.B. 1991. The effect of tick infestation on the production of cows of three breeds of cattle. Onderstepoort Journal of Veterinary Research, 58:71-74.

STEYN, G.J. [1988]. A farming systems study of two rural areas in the Peddie district of Ciskei. D.Sc. thesis, University of Fort Hare.

SUTHERST, R.W., MAYWALD, G.F., KERR, J.D. \& STEGEMAN, D.A. 1983. The effect of cattle tick (Boophilus microplus) on growth of Bos indicus X B taurus steers. Australian Journal of Agricultural Research, 34:317-327.

UILENBERG, G. 1992. Economics, epidemiology and ecology: a multidisciplinary approach to the planning and appraisal of tick and tick-borne disease control in Southern Africa, in Tick vector biology, medical and veterinary aspects, edited by $\mathrm{B}$. Fivaz, T. Petney \& I. Horak. Berlin: Springer-Verlag. 